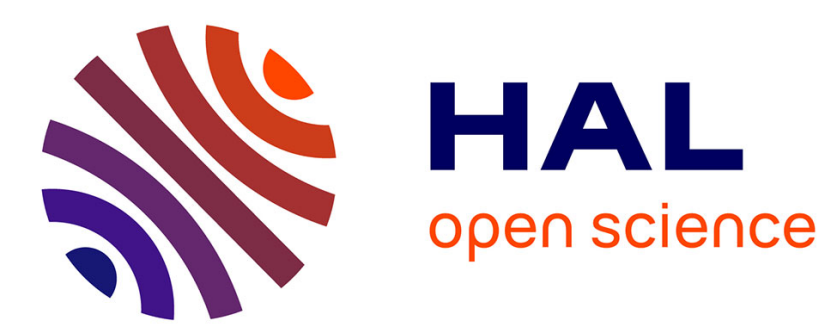

\title{
Orientation Determination of a Scatterer Based on Polarimetric Radar Measurements
}

\author{
Nicolas Barbot, Olivier Rance, Etienne Perret
}

\section{To cite this version:}

Nicolas Barbot, Olivier Rance, Etienne Perret. Orientation Determination of a Scatterer Based on Polarimetric Radar Measurements. URSI GASS 2020, Aug 2020, Rome, Italy. hal-02948679

\section{HAL Id: hal-02948679 \\ https://hal.science/hal-02948679}

Submitted on 24 Sep 2020

HAL is a multi-disciplinary open access archive for the deposit and dissemination of scientific research documents, whether they are published or not. The documents may come from teaching and research institutions in France or abroad, or from public or private research centers.
L'archive ouverte pluridisciplinaire HAL, est destinée au dépôt et à la diffusion de documents scientifiques de niveau recherche, publiés ou non, émanant des établissements d'enseignement et de recherche français ou étrangers, des laboratoires publics ou privés. 


\title{
Orientation Determination of a Scatterer Based on Polarimetric Radar Measurements
}

\author{
Nicolas Barbot ${ }^{(1)}$, Olivier Rance ${ }^{(1)}$ and Etienne Perret ${ }^{(1)}$ \\ (1) Univ. Grenoble Alpes, Grenoble INP, LCIS \\ F-26000 Valence, France
}

\begin{abstract}
This paper presents a theoretical model to extract the orientation of any scatterer under normal incidence. Analytical expressions are given for mono-static configuration in co-polarization and can easily be extended in crosspolarization. The proposed approach is particularly interesting to determine chipless tag orientation, i.e., to use a chipless tag as an orientation sensor. Since the method is valid for any scatterer, antenna mode do not have to be separated from the structural mode before estimation, thus the proposed approach can directly be applied on raw signal without time gating. Measurements in anechoic chamber are done to evaluate the performance of the proposed solution.
\end{abstract}

\section{Introduction}

Chipless RFID technology has been classically used to identify items at a very low cost. Nowadays, recent developments have been realized on this technology to address new applications such as sensing. In addition to the ID of the label which is directly encoded within the tag geometry, the backscattered signal also conveys information about the surrounding environment. This latter information can be exploited at the reader side to add sensing capability to tags initially designed for identification purposes.

Chipless technology brings many perspectives for sensing applications such as contactless measurements, low-cost realization, and batteryless operation. Moreover chipless based sensors can easily be placed in harsh environments contrary to classical electronic sensors. Lot of different designs have already been proposed by researchers for temperature [1-3], humidity [4], gas detection [5], level of fluids [6] and positioning [7]. In the case of orientation sensing, amplitude variation has been mainly used to estimate the angle information. In [8], authors have designed a copolarization chipless tag based on a $\mathrm{C}$-shape tag with a resolution of $20^{\circ}$. In [9-11], authors have developed an orientation sensor in cross-polarization, but the lack of analytical model restricts the use of the sensor. In [12] authors introduced an analytical model to extract the orientation, however this model is limited to dipole-like scatterer.

This paper introduces a general model allowing to extract the orientation without making any assumption on the chipless tag (or scatterer) used. Moreover, this technique does not require time gating operation to separate the antenna mode and the structural mode and can be applied directly on the tag response. An orientation error lower than $3^{\circ}$ in a range of $90^{\circ}$ is obtained.

The paper is organized as follows, in Section 2, the analytical expressions used to extract the tag orientation from the measured polarization scattering parameters are introduced. In Section 3, measurements are presented for orientation sensing in anechoic chamber. Finally, Section 4 concludes the paper.

\section{Theory}

The description of the interaction of a wave with a chipless tag is described by its polarization scattering matrix $\mathbf{S}$ which links the scattered electric field vector $E^{r}$, to the incident field vector $E^{i}$ in vertical $v$ and horizontal $h$ polarizations:

$$
\left[\begin{array}{l}
E_{v}^{r} \\
E_{h}^{r}
\end{array}\right]=\left[\begin{array}{ll}
S_{v v} & S_{v h} \\
S_{h v} & S_{h h}
\end{array}\right] \cdot\left[\begin{array}{l}
E_{v}^{i} \\
E_{h}^{i}
\end{array}\right]
$$

where each component in the $\mathbf{S}$ matrix is complex and frequency dependent. Note that since chipless tags are passive and reciprocal, $\mathbf{S}$ is symmetric i.e., $S_{v h}=S_{h v}$. Moreover, (1) is valid for any scatterer.

If we consider a rotation of the tag by an angle $\theta$ under normal incidence, we can show that the parameters of the $\mathbf{S}$ matrix at $\theta$ are linked to the initial ones by the following expression [13]:

$$
\mathbf{S}(\theta)=\Omega^{T} \cdot \mathbf{S} \cdot \Omega
$$

where $^{T}$ is the transpose operator and $\Omega$ is a rotation matrix defined by:

$$
\Omega=\left[\begin{array}{cc}
\cos \theta & -\sin \theta \\
\sin \theta & \cos \theta
\end{array}\right]
$$

From (2), expression of $S_{v v}(\theta)$ can be written as:

$$
S_{v v}(\theta)=S_{v v} \cos ^{2} \theta+S_{v h} \sin 2 \theta+S_{h h} \sin ^{2} \theta
$$

By reducing the power of $\cos ^{2}$ and $\sin ^{2}$ and setting $\tan \theta=t$ (with $\sin 2 \theta=\frac{2 t}{1+t^{2}}$ and $\cos 2 \theta=\frac{1-t^{2}}{1+t^{2}}$ ), (4) can be rewritten:

$$
\left(S_{v v}(\theta)-S_{h h}\right) t^{2}+2 S_{v h} t+\left(S_{v v}(\theta)-S_{v v}\right)=0
$$




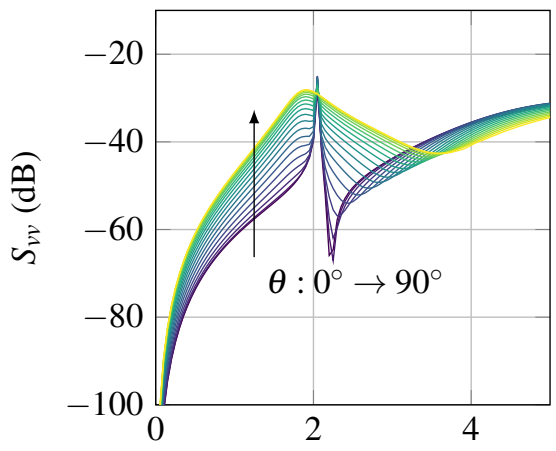

(a) Frequency $(\mathrm{GHz})$

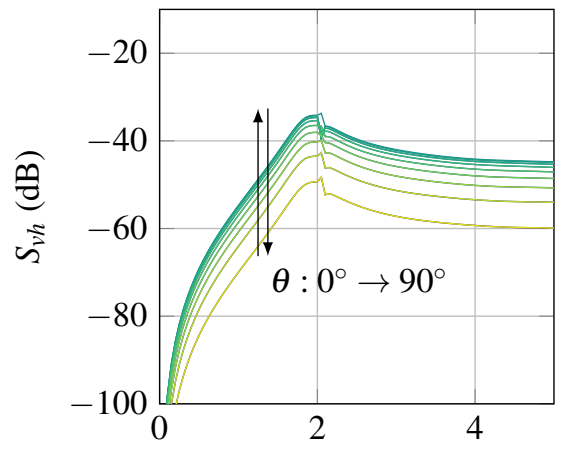

(b) Frequency $(\mathrm{GHz})$

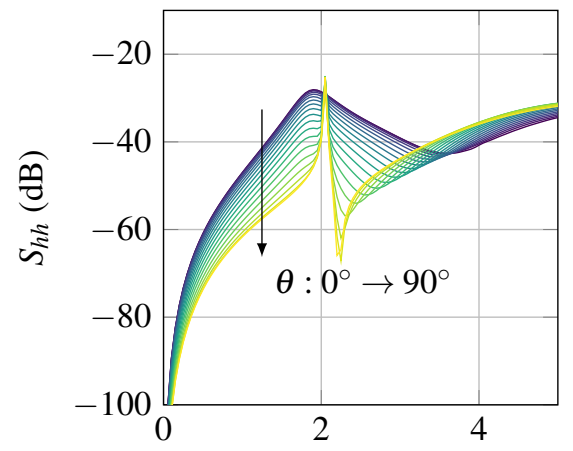

(c) Frequency $(\mathrm{GHz})$

Figure 1. Simulated polarization scattering parameters of the loop resonator in (a) vertical co-polarization, (b) crosspolarization and (c) horizontal co-polarization for $\theta \in\left[0^{\circ} ; 90^{\circ}\right]$.

where we can recognize a classical second order polynomial of real variable $t$ with complex coefficients. Solutions of this polynomial can be expressed as:

$$
t_{1,2}=\frac{-2 S_{v h} \pm \sqrt{\Delta}}{2\left(S_{v v}(\theta)-S_{h h}\right)}
$$

where $\Delta=\left(2 S_{v h}\right)^{2}-4\left(S_{v v}(\theta)-S_{h h}\right)\left(S_{v v}(\theta)-S_{v v}\right)$. Finally, $\theta$ can be extracted from $t_{1,2}$ :

$$
\hat{\theta}=\arctan \left(t_{1,2}\right)
$$

Note that this expression can recover the orientation of a tag from the knowledge of the full scattering matrix $\mathbf{S}$ at a known orientation (i.e., 3 reference measurements: $S_{v v}$, $S_{v h}$, and $S_{h h}$ ) and one measurement in co-polarization (i.e., $S_{v v}(\theta)$ ) at an unknown orientation $\theta$. This determination is valid for any scatterer.

Fig. 1 presents the simulation of the polarization scattering parameters in vertical co-polarization $(v v)$, crosspolarization $(v h)$ and horizontal co-polarization $(h h)$ as a function of the frequency for the loop resonator [see Fig. 2(a)]. The loop resonance is observed around $2 \mathrm{GHz}$ by looking at $S_{v v}\left(0^{\circ}\right)$ or $S_{h h}\left(90^{\circ}\right)$. For the orthogonal orientation (i.e. $S_{v v}\left(90^{\circ}\right)$ and $S_{h h}\left(0^{\circ}\right)$ ), response is close to a dipole one (this orientation is generally not used to encode information). On the other side, cross-polarization is maximum at $\theta=45^{\circ}$ and null at $0^{\circ}$ and $90^{\circ}$ due to the symmetry of the structure. Note that at the resonant frequency and at $\theta=0^{\circ}, S_{h h}$ cannot be neglected in front of $S_{v v}$ whereas $S_{v h}$ is null, thus the scattering matrix $\mathbf{S}$ is described by 2 nonzero parameters. Finally, note that this scatterer is different from the dipole chipless tag studied in [12] which can be described by a polarization scattering matrix with a single non-zero parameter.

\section{Measurements}

Realized tag used for orientation determination is presented in Fig. 2(a). The tag is composed by a single loop resonator in copper and a $0.8 \mathrm{~mm}$ thickness Roger $4003 \mathrm{C}$ substrate

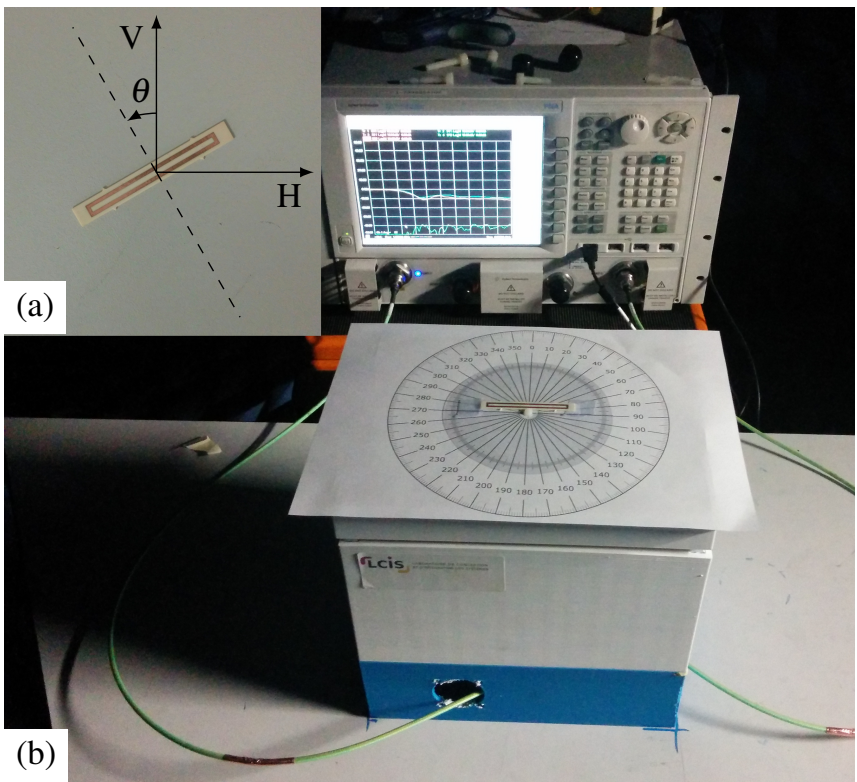

Figure 2. (a) Loop resonator used for orientation measurement. (b) Measurement bench based on a mono-static configuration with a dual polarization antenna.

without any ground plan. External loop dimensions are $60 \times 5 \mathrm{~mm}$ with an inner gap of $57 \times 2 \mathrm{~mm}$.

The measurement bench is presented in Fig. 2(b) and has been used to measure the backscattered field in all polarization $(v v, v h$, and $h h)$ at a distance of $10 \mathrm{~cm}$ from the antenna. At these distances, the tag is in the radiating near field of the antenna [14]. Measurements have been done using the Vector Network Analyzer (VNA) N5222A and a dual-access dual-polarization antenna (Satimo QH2000). For comparison purposes, full wave simulations using CST Microwaves with transient solver have also been performed. Note that time gating has not been used (in neither simulation nor measurement).

The impact of the tag orientation on the measured peak apex magnitude is represented in Fig. 3 as a function of the ori- 


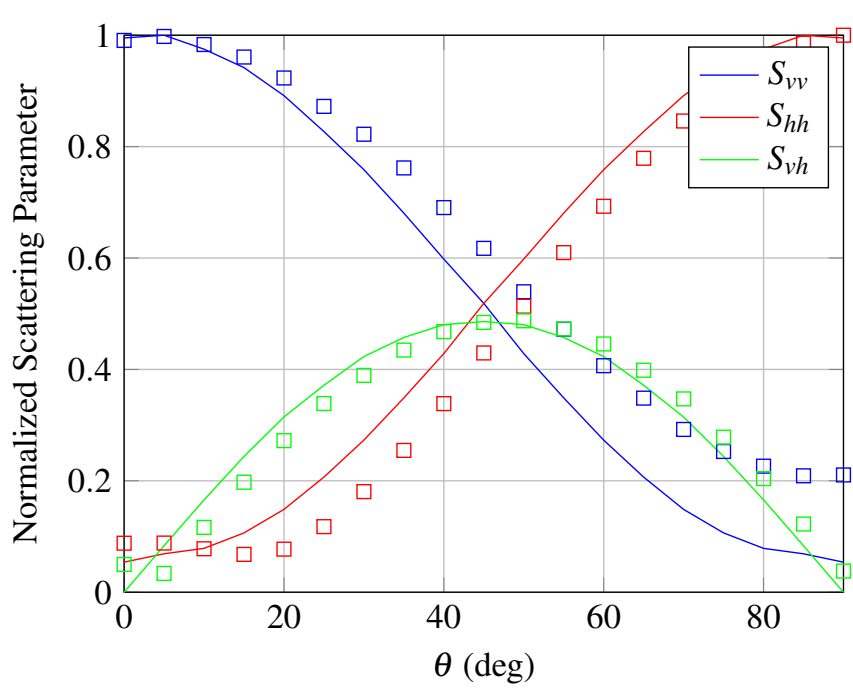

Figure 3. Polarizaton scattering parameter peak apex value with respect to orientation $\theta$, in vertical co-polarization, cross-polarization and horizontal co-polarization for the tag presented in Fig. 2(a). Simulation in plain line, measurements in square marks.

entation $\theta$. Measurements have been realized in anechoic chamber and is also compared with simulations. For comparison purposes, all results have been normalized to 1 . The offset present in $S_{v v}$ and $S_{h h}$ is due to the fact that at $\theta=0^{\circ}$ (resp. $\theta=90^{\circ}$ ), $S_{h h}$ cannot be neglected in front of $S_{v v}$ (resp. $S_{v v}$ cannot be neglected in front of $S_{h h}$ ). Note that this offset is not present in cross-polarization.

As described in Section II, the tag orientation can be determined using (7). Reference measurements have been chosen at $\theta=0^{\circ}$, and orientation has been estimated from the vertical co-polarization measurement. Orientation estimation $\hat{\theta}$, obtained in anechoic chamber is plotted in Fig. 4 as a function of the real value of $\theta$. Orientation can be accurately derived in the interval $\left[0^{\circ} ; 90^{\circ}\right]$. In both cases, average value of the absolute orientation error is equal to respectively $0.53^{\circ}$ and $2.70^{\circ}$ in simulation and measurement over the complete interval. Thus, the proposed approach permits to recover the orientation of any scatterer over a $90^{\circ}$ interval with an error less than $3^{\circ}$.

\section{Conclusion}

In this paper, we have presented a method which allows to extract the orientation of any chipless tag based on the knowledge of its polarization scattering matrix and a measurement of its co-polarization response in an unknown orientation. Error in anechoic chamber is less than $3^{\circ}$ over an $90^{\circ}$ interval. Moreover, since sensing is based in on amplitude and phase variation, the same resonators can be used for both identification and sensing without reducing the coding capacity.

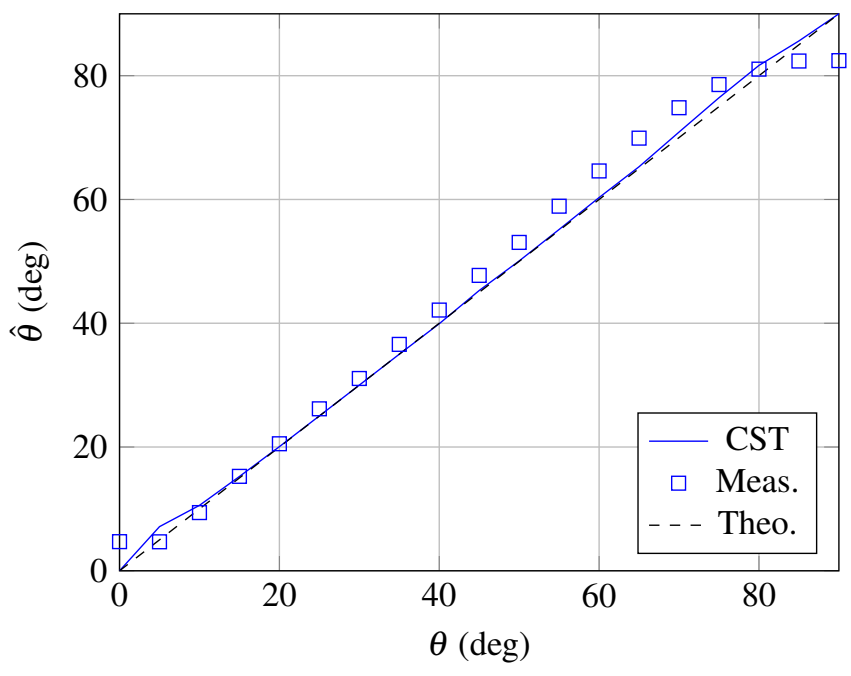

Figure 4. Orientation estimation as a function of the true orientation of the sensor in simulation and measurement for the tag presented in Fig. 2(a).

\section{Acknowledgments}

This research was funded by the European Research Council (ERC) under the European Union's Horizon 2020 research and innovation program (grant $\mathrm{N}^{\circ} 772539$ ).

\section{References}

[1] D. Girbau, Á. Ramos, A. Lazaro, S. Rima, and R. Villarino, "Passive wireless temperature sensor based on time-coded UWB chipless RFID tags," IEEE Trans. Microw. Theory Techn., vol. 60, no. 11, pp. 36233632, 2012.

[2] B. Kubina, M. Schusler, C. Mandel, A. Mehmood, and R. Jakoby, "Wireless high-temperature sensing with a chipless tag based on a dielectric resonator antenna," in SENSORS, 2013 IEEE, Nov. 2013, pp. 1-4.

[3] E. M. Amin and N. Karmakar, "Development of a chipless RFID temperature sensor using cascaded spiral resonators," in SENSORS, 2011 IEEE, Oct. 2011, pp. 554-557.

[4] Y. Feng, L. Xie, Q. Chen, and L.-R. Zheng, "Low-cost printed chipless RFID humidity sensor tag for intelligent packaging," IEEE Sensors J., vol. 15, no. 6, pp. 3201-3208, 2015.

[5] A. Vena, L. Sydänheimo, M. M. Tentzeris, and L. Ukkonen, "A fully inkjet-printed wireless and chipless sensor for $\mathrm{CO}_{2}$ and temperature detection," IEEE Sensors J., vol. 15, no. 1, pp. 89-99, 2015.

[6] A. Guillet, A. Vena, E. Perret, and S. Tedjini, "Design of a chipless RFID sensor for water level detection," in 201215 International Symposium on Antenna Technology and Applied Electromagnetics, June 2012, pp. $1-4$. 
[7] N. Barbot and E. Perret, "A chipless RFID method of 2D localization based on phase acquisition," Journal of Sensors, vol. 2018, p. 6, 2018. [Online]. Available: https://www.hindawi.com/journals/ js/2018/7484265/cta/

[8] A. Vena, E. Perret, and S. Tedjini, "A compact chipless RFID tag using polarization diversity for encoding and sensing," in 2012 IEEE International Conference on RFID (RFID), April 2012, pp. 191-197.

[9] S. Genovesi, F. Costa, M. Borgese, A. Monorchio, and G. Manara, "Chipless RFID tag exploiting crosspolarization for angular rotation sensing," in 2016 IEEE International Conference on Wireless for Space and Extreme Environments (WiSEE), Sept. 2016, pp. $158-160$.

[10] S. Genovesi, F. Costa, M. Borgese, F. A. Dicandia, A. Monorchio, and G. Manara, "Chipless RFID sensor for rotation monitoring," in 2017 IEEE International Conference on RFID Technology Application (RFID-TA), Sept. 2017, pp. 233-236.

[11] S. Genovesi, F. Costa, M. Borgese, F. A. Dicandia, and G. Manara, "Chipless radio frequency identification (RFID) sensor for angular rotation monitoring," Technologies, vol. 6, no. 3, 2018. [Online]. Available: http://www.mdpi.com/2227-7080/6/3/61

[12] N. Barbot, O. Rance, and E. Perret, "Angle sensor based on chipless RFID tag," IEEE Antennas and Wireless Propagation Letters, pp. 1-1, 2019.

[13] E. F. Knott, J. F. Shaeffer, and M. T. Tuley, Radar cross section. SciTech Publishing, Inc., 2004.

[14] A. Yaghjian, "An overview of near-field antenna measurements," IEEE Trans. Antennas Propag., vol. 34, no. 1, pp. 30-45, January 1986. 